\title{
MAGNETOHYDRODYNAMIC PROJECTS AT THE CDIF
}

\author{
Quarterly Technical Progress Report \\ for \\ Apri1 1 - June 30, 1991
}

\section{PREPARED BY}

MSE, Inc .

P.0. Box 3767

Butte, Montana 59702

\section{PREPARED FOR}

U.S. Department of Energy

Under Contract DE-ACO7-88ID12735

\section{MASTER}

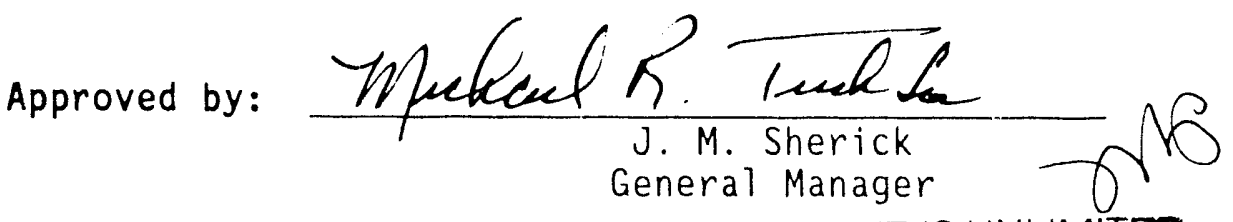




\section{ABSTRACT}

This quarterly technical progress report presents the tasks accomplished at the Component Development and Integration Facility during the second quarter of FY91. Areas of technical progress this quarter included:

- coal system development;

- $\quad$ seed system development;

- test train/A-Bay modifications;

- channel power dissipation and distribution system development;

- oxygen system storage upgrade;

- iron-core magnet thermal protection system checkout;

- TRW slag rejector/CDIF slag removal project;

- Data Acquisition System;

- stack gas/environmental compliance upgrade;

- coal-fired combustor support;

- 1 A channels fabrication and assembly;

- support of Mississippi State University diagnostic testing;

- test operations and results;

- data analysis and modeling;

- technical papers; and

- projected activities. 


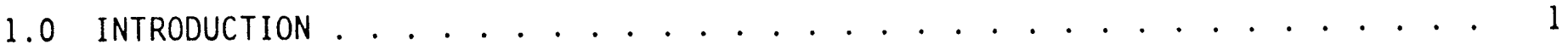

2.0 TASK DEFINITION . . . . . . . . . . . . . . . . . . . . . . . . . 1

2.1 Task 1.. Facility . . . . . . . . . . . . . . . . . . 1

2.1.1 Subtask 1A - C Coal System Development . . . . . . . . . 2

2.1.2 Subtask 1B - - Seed System Development . . . . . . . . . . . . 2

2.1.3 Subtask 1C - - Test Bay Modification . . . . . . . . . . . 2

2.1.4 Subtask 1D -. Channel Power Dissipation and Distribution
System (CPDDS) Development .... 3

2.1.5 Subtask 1E -- Integrated Topping Cycle (ITC) Current . . . . . 3

2.1.6 Subtask 1F - - Solid Suspension Injection System Upgrade . . . 4

2.1.7 Subtask 1G -. Oxygen System Storage Upgrade . . . . . . . . . 4

2.1.8 Subtask IH -- Iron-Core Magnet (ICM) Thermal Protection

2.1.9 Subtask 1I - S TRW Slag Rejector/CDIF siag Removai Project . . 5

2.1.10 Subtask 1J -. Data Acquisition System (DAS) ....... 5

2.2 Task 2 .. Test Hardware/Support . . . . . . . . . . . . . . 6

2.2.1 Subtask 2A - - Stack Gas/Environmental Compliance Upgrade . . . 6

2.2.2 Subtask 2B - - Coal-Fired Combustor (CFC) Support . . . . . . 7

2.2.3 Subtask 2 C . - 1A Channels Fabrication and Assembly ..... . 7

2.2 .4 Subtask 2D -. Unassigned . . . . . . . . . . . . 8

2.2 .5 Subtask $2 E$-. Unassigned . . . . . . . . . . . . . . . 8

2.2.6 Subtask $2 F$ - - Support of Mississippi State University
(MSU) Diagnostic Testing . . . . . . 8

2.3 Task 3 -. Test Operation ................ 8

2.3.1 Subtask 3A - - Test Operations and Results . . . . . . . . 9 9

2.3.2 Subtask 3B .. Unassigned ............. . 12

2.3.3 Subtask 3C - Data Analysis and Modeling . . . . . . . 12

3.0 TECHNICAL PAPERS . . . . . . . . . . . . . . . . . . . . . . . . . 16

4.0 PROJECTED ACTIVITIES . . . . . . . . . . . . . . . . . . . . 16 


\subsection{INTRODUCTION}

The Component Development and Integration Facility (CDIF) is a major U.S. Department of Energy magnetohydrodynamic (MHD) test facility in Butte, Moritana. The CDIF is operated by MSE, Inc. Within the national MHD program, MSE personnel are responsible for performing integration testing of vendor-supplied MHD power train components at the CDIF to support the goal of commercialization.

During the third quarter of FY9l, MHD testing and testing to obtain material and design information was reinitiated. Channel coupon replacement was completed, and testing was reinitiated to 1) obtain material and design information, 2 ) check out the slag rejector, and 3 ) study seed utilization and coal fines. Before the end of the quarter, testing was shut down as scheduled for installation of a new Data Acquisition System (DAS). The channel was reroved for channel coupon inspection and channel refurbishment. In addition to installing the new DAS, activities such as rebuilding the channel, investigating and repairing the magnet leak, and modifying systems were begun.

\subsection{TASK DEFINITION}

- Task 1 -. Facility;

- Task 2 - - Test Hardware/Support; and

- Task 3 -. Test Operation.

\subsection{TASK 1 - FACILITY}

This task encompassed modifications and enhancements to plant systems that support testing, including checkout, testing, and characterization.

Subtasks for the facility task were:

- Subtask 1A - Coal System Development;

- Subtask 1B - - Seed System Development;

- Subtask 1C -- Test Train/A-Bay Modifications;

- Subtask 10 -- Channel Power Dissipation and Distribution System (CPDDS) Development;

- Subtask IE - Integrated Topping Cycle (ITC) Current Consolidators;

- Subtask IF -- solid Suspension Injection System Upgrade;

- Subtask 1G -- Oxygen System Storage Upgrade;

- Subtask IH -. Iron-Core Magnet (ICM) Thermal Prutection System Checkout;

- Subtask 1I - . TRW Slag Rejector/CDIF Slag Removal Project; and

- Subtask 1J -. Data Acquisition System (DAS). 


\subsubsection{Subtask 1A - Coal System Development}

The following progress was made during coal system development.

- Engineering work continued on six of the eight coal-related projects. A work package was issued, and work was completed for the primary injector screen project. Work packages were issued (with installation scheduled for the future) for the storage and primary injector vent lines, pulverizer feeder pluggage, and storage injector level switch projects.

- An analysis of the CDIF cual processing system was performed by $A B B$ Raymond, and a report that included a mass balance on the system was issued.

- Design work was completed for installirig rupture disks on the coal and seed pressure vessels, and materials are being procured.

\subsubsection{Subtask 1B -- Seed System Development}

The following progress was made during seed system development.

- Design work to increase the capacity of the seed storage silo rotary feeder is approximately 35 percent complete.

- Design work was completed for converting the fly ash storage bin to a dust collector. Materials were procured, and installation is being scheduled.

- The Title I design package for replacing the seed storage silo discharge piping is approximately 90 percent complete.

- Design work for providing a nitrogen purge to the inlet of the seed transfer blower is 85 percent complete.

- The vertical plate was installed in the cone of the seed storage silo.

\subsubsection{Subtask 1C -. Test Train/A-Bay Modifications}

This subtask is an ongoing design effort to support the CDIF Proofof-Concept (POC) Program.

During the past quarter, the conceptual design review for the test train/A-Bay modifications was held. The test train/A-Bay modifications project consists of the following subtasks:

- workhorse combustor and channel removal;

- integrated topping cycle (ITC) POC combustor and channel installation; 
- primary cooling water modifications;

- low-pressure cooling system installation;

- test train instrumentation; and

- process flow piping modifications.

The Title I design is scheduled to be completed during July, and Title II design is scheduled to be completed in October. Installation of the ITC POC combustor is scheduled to be completed in March 1992, and installation of the $1 \mathrm{~A}_{4}$ channel is scheduled to be completed in May 1992.

\subsubsection{Subtask 1D -- Channel Power Dissipation and Distribution System (CPDDS) Development}

The CPDDS consists of the resistive load bank, high-voltage room (HVR), inverter, voltage limiting device, and wiring from the HVR to the MHD channel connectors. The following progress was made in the CPDDS this quarter.

- Removed CCR+15, configuration work package from the HVR to support the MHD (nonpower) test series.

- Installed a conductivity configuration work package and provided configuration drawings and test support. Troubleshooting and configuration adjustments were completed as necessary.

- Ordered spare parts for the inverter battery charger system. Created sole-source justification for HVR current sensors, designed LEM adapter plates, ordered 40-amp fuses, high-voltage scaling resistors, 500 -volt bipolar meter scales to support $1 A_{1}$ power configuration and special instrumentation requests.

- Completed as-built drawings for the HVR upper and lower panels for panels $\mathrm{H}, \mathrm{J}$, and $\mathrm{K}$. Permanently installed a current shunt and meter in the meter panel in the diffuser circuit located on panel A.

\subsubsection{Subtask 1E -- Integrated Topping Cycle (ITC) Current Consolidators}

The Title I current consolidators (KCS) design package was presented to the MSE Design Review Commitree on May 9. All comments and concerns on the Title I design were addressed and will be incorporated into the Title II design. The Title II presentation is tentatively scheduled for the end of July. The work package that provided an isolated 120 -volt source for the diode stacks in the HVR was completed; this package was approved for installation during the Title I review.

Project assessment of the $K C$ building design revealed that the initial design concept of placing a single building adjacent to 
Building 50 was not possible during the timeframe allowed. Subsequently, an alternative plan of action was developed and implemented, and an informational design review was held on May 31. A proposal for purchasing two prefabricated buildings (one for anode cabinets and one for cathode cabinets and control room) was accepted. Design and specification development for the first building has begun. Building completion is scheduled for September 1 .

\subsubsection{Subtask 1F -- Solid Suspension Injection System Upgrade}

The Title I design review for upgrading the solid suspension injection system was completed on April 29. The detailed Title II design for this project is currently in progress, and the presentation to the Design Review Committee is expected to be done in September.

The scope of this project includes installing four additional progressive cavity pumps to meet the TRW requirement of 1 to 4 pounds per minute injection rates at each combustor port. Instrumentation will be installed to 1) monitor flow rates from each progressive cavity pump and 2) monitor injection pressures at each port.

\subsubsection{Subtask 1G - - Oxygen System Storage Upgrade}

The two 55,000-galion liquid oxygen storage tanks were off-loaded from railicars on April 3 and 4 . The tanks were placed on cribbing in an area where the subcontractor could access and relocate them to the support piers. Rereiving and engineering inspections found the tanks unsatisfactory, and all findings were transmitted to Minnesota Valley Engineering (MVE), the tank manufacturer. MVE provided on-site support, and all deficiencies were corrected. Specifications for two additional 55,000-gallon liquid oxygen storage tanks were issued to procurement on May 24 . Bids for fabricating these tanks are currently being received. Structural steel pipe supports were erected, and some shop-fabricated pipe spools were installed. Two sets of concrete piers were poured, and a temporary roadway was constructed for the scheduled July 9 installation of the two 55,000-gallon storage tanks. Piping, structural steel, concrete, and electrical work continues.

\subsubsection{Subtask 1H -- Iron-Core Magnet (ICM) Thermal Protection System Checkout}

On February 5, 1991, the ICM developed a leak in a cooling tube of the second pancake of the west coil. In addition, the east coil displayed a loss of insulation integrity. Since that time, efforts to repair the damage have continued.

A parallel repair plan for the west coil was implemented to consider replacing, isolating, or repairing the coil using internal 
repair techniques. Internal repair was the preferred approach; however, Dr. Bradford Smith of the Massachusetts Institute of Technology was contracted to design an isolation jumper as a backup repair.

Two firms capable of performing an internal repair, National Nuclear Co. and Innovation Services Inc., are competitively bidding for the repair job. Both firms are required to submit repair evaluation coupons as part of the bid proposal, and these coupons will be tested by MSE to determine the suitability of the proposed repairs. The proposals are due July 15.

Corrosion, thermal, electrical, flow, and chemical studies of the magnet are continuing. These studies are intended to help determine the root cause of the leak and to provide insight for repairing the east coil.

\subsection{Subtask 1I -- TRW Slag Rejector/CDIF Slag Removal Project}

The TRW slag rejector consists of a slag grinder assembly, a densephase pneumatic transport vessel, and an atmospheric collection tank with interconnecting valves and piping. The CDIF slag removal system will consist of a dewatering conveyor and a dense-phase pneumatic transport system as well as the associated mechanical, electrical, and control systems. The slag removal system will dewater, weigh, and transport the slag out of Building 60 to disposal storage pads. When installed, the slag rejector/removal equipment will provide batch removal and slag weighing from the TRW $50-M W_{t}$ coal-fired combustor to support extended duration testing.

Activities this past quarter include:

- Completing installation and startup of the TRW slag rejection portion of the project.

- Completing the engineering work for the Phase III covered work package.

- Continuing engineering work for the electrical and instrumentation and control (I\&C) packages of the slag removal system.

- Continuing procurement of the dense-phase pneumatic transport system.

\subsubsection{Subtask 1J -- Data Acquisition System (DAS)}

A new DAS was purchased for the CDIF. This system replaces the old DAS that could not be upgraded or expanded to be compatible with new technology, was limited in capability, and could only perform data acquisition. 
The new DAS has increased capability and greater power than the old DAS, it allows for more inputs, has greater on-line display/ analysis capability, performs data acquisition more efficiently on more input/parameters, and provides off-line analysis and report generation.

During this reporting period, Factory Acceptance Test Procedures were finalized, and a copy of the procedures was sent to Dr. Al Plantz at the Pittsburgh Energy Technology Center in preparation for his participation in the Factory Acceptance Tests, which were held at Datacom in Fort Walton Beach, Florida.

The old DAS was removed to prepare for arrival of the new DAS at the CDIF.

During June, the Factory Acceptance Test Procedures were conducted, and 17 of 23 procedures were successfully completed. Due to power interruption at Datacom, MSE personnel requested the system be packaged and shipped to the CDIF where the Factory Acceptance Test Procedures could be completed after the system was installed and connected to an uninterruptable power supply.

The system will be shipped on July 5 and will arrive at the CDIF on July 9. Two weeks of factory installation and checkout are planned after which the test procedures will begin; this approach will allow the baseline schedule to be maintained as planned.

\subsection{TASK 2 -- TEST HARDWARE/SUPPORT}

Test hardware is supplied under a Department of Energy contract and is tested at the CDIF. During the test program, hardware design modifications and repairs are accomplished by MSE personnel at the request of the component developer. Facility test hardware interface refinements are also part of this task. Subtasks for the test hardware/support task were:

- Subtask 2A -- Stack Gas/Environmental Compliance Upgrade;

- Subtask 2B -- Coal-Fired Combustor (CFC) Support;

- Subtask 2C -- IA Channels Fabrication and Assembly;

- Subtask 20 -- Unassigned;

- Subtask 2E -- Unassigned; and

- Subtask 2F - - Support of Mississippi State University (MSU) Diagnostic Testing.

\subsubsection{Subtask 2A - - Stack Gas/Environmental Compliance Upgrade}

This upgrade provides a permanent facility for collecting and analyzing off gases from any process tested at the CDIF. It will also give the CDIF the needed modification to comply with the 
required safety standards for storing and dispensing compressed gases and to comp?y with the Code of Federal Regulations (40 CFR $60)$ and the State of Montana's Administrative Rules of Montana (ARM 16.8) for stack discharges for oxides of nitrogen, sulfur dioxide, and carbon monoxide as stated in the State of Montana Department of Health and Environmental Sciences permit number 1528-A issued to the CDIF.

Work was completed for the Stack Gas/Environmental Compliance Upgrade, and the system is being operationally checked out. Once checkout is complete, this subtask will be knowi as Air Emissions Monitoring Support. An independent relative accuracy test audit will be performed on the continuous emissions monitoring system per the Quality Assurance Project Plan for the MHD Continuous Emissions Monitoring System, 2DOE-MHD-D166.

As part of the air emissions monitoring support, an air emissions inventory was conducted at the CDIF Coal Preparation Plant (Building 20) during April and May. The four exhaust streams in Building 20 were successfully sampled for particulate matter, and one of the exhaust streams was sampled for volatile organic compound emissions.

With the addition of a hydrogen analyzer, work is continuing on monitoring and analyzing off gases for carbon monoxide, carbon dioxide, oxygen, and hydrogen on a dry basis and sulfur dioxide, carbon monoxide, and oxides of nitrogen on a wet basis.

During May, the MHD stack was successfully sampled at one of the available four sampling ports to obtain baseline data for particulate before the upcoming special projects test series scheduled this fall.

\subsubsection{Subtask 2B -- Coal-Fired Combustor (CFC) Support}

Before testing in April, the CFC was refitted with a refurbished head end plate and coal injector. Also in this timeframe, a coupon filler section was installed to evaluate prototypic metal overiays. The filler section temperature was monitored during testing and shutdown to determine the environment on the backside of the sections. Upon shutdown, a portion of the filler section was heated to prevent acid condensation in the filler section.

Upon completion of testing in May, the second stage was removed and stored, and the coupon filler section was removed and sent to TRW.

\subsubsection{Subtask 2C - 1 A Channels Fabrication and Assembly}

The materials test channel was installed into the test train in early April. Tiris channel contained various Textron Defense Systems (TDS)-supplied test bars and Z-bar sections in the right and left forward sidewall section and forward aft anode. The channel consisted of wall sections $49,58,19,20,29,30,31$, and 
32. The thermal and electrical power test history of these wall sections is shown in Table 1.

TABLE 1 .. CHANNEL WALL SECTIONS IN SERVICE DURING QUARTER

\begin{tabular}{||c|l|c|c||}
\hline $\begin{array}{c}\text { WALL SECTION } \\
\text { NUMBER }\end{array}$ & \multicolumn{1}{|c|}{ DESCRIPTION } & $\begin{array}{c}\text { COAL } \\
\text { HOURS }\end{array}$ & $\begin{array}{c}\text { POWER } \\
\text { HOURS }\end{array}$ \\
\hline 49 & FORWARD ANODE & $30: 17$ & $00: 00$ \\
\hline 58 & AFT ANODE & $30: 17$ & $00: 00$ \\
\hline 19 & FORWARD CATHODE & $260: 39$ & $153: 44$ \\
\hline 20 & AFT CATHODE & $260: 39$ & $153: 44$ \\
\hline 29 & FORWARD RIGHT SIDEWALL & $27: 18$ & $22: 30$ \\
\hline 30 & AFT RIGHT SIDEWALL & $243: 16$ & $146: 14$ \\
\hline 31 & FORWARD LEFT SIDEWALL & $97: 34$ & $57: 24$ \\
\hline 32 & AFT LEFT SIDEWALL & $243: 16$ & $146: 14$ \\
\hline
\end{tabular}

The channel was removed from service after 30 hours 17 minutes of thermal service.

All sidewall test bars were shipped to TDS after the channel was removed. The test bars will be reinstalled the first week of August for the channel to be used during fall testing.

In-house fabrication of replacement diffuser sections is complete, and the sections were installed in the test train. A water balance of the system was completed to ensure adequate water flow.

\subsubsection{Subtask 2D _-. Unassigned}

\subsubsection{Subtask 2E -- Unassigned}

\subsubsection{Subtask 2F -- Support of Mississippi State University (MSU) Diagnostic Testing}

No activity took place under this subtask during this reporting period.

\subsection{TASK 3 -- TEST OPERATION}

The subtasks for the test operation task were:

- Subtask 3A -- Test Operations and Results; 
- Subtask 38 -- Unassigned; and

- Subtask 3C -- Data Analysis and Modeling.

\subsubsection{Subtask 3A-- Test Operations and Results}

Test objectives addressed during the quarter included:

- Checking out the slag rejector system under thermal operation of the CFC.

- Evaluating combustor filler coupon corrosion.

- Evaluating channel braze integrity and completing post-tist observation of the channel Z-walls for water leaks.

- Checining out the slag rejector system with the conductivity power supply by completing three continuous slag cullection tank cycles.

- Obtaining data for a thorough evaluation of the baseline seed injertion method.

- Obtaining data for Endress+Hauser meter calibration efforts.

- Obtaining slag information for precombustor-only operation.

- Obtaining data to determine the effect of increasing seed oxygen flow.

- Obtaining heat flux, conductivity, and slag rejection data with CDIF baghouse coal fines reintroduced into the normal coal product used for testing at the CDIF. The fines will be reintroduced at a 15 to 20 percent mix of fines.

Testing this quarter included nine tests for a total coal burn time of 30 hours 17 minutes. No power testing was completed during this series. Table 2 outlines the tests run durirg the quarter.

As a result of testing, on-line observations were made and probable causes were determined. The following addresses some of the observations.

Test 91-SREJ-2 completed the nonelectrical portion of the shakedown testing for Phase II of the continuous slag rejection system.

Chanyes to the control software resulting from test 91-SREJ-1 were implemented; problems experienced during that test were corrected. criterion for this test was successful completion of eight denseveyor and three collection tank dumps. The first collection tank dump occurs after two denseveyor dimp cycles; subsequent collection tank dumps occur after three denseveyor duinp cycles. During the test, the first automatic denseveyor dump appeared to operate correctly; however, post-test data analys is showed it did not. The second cycle, which was to have included a collection 
TABLE 2 .. MHD TESTS

\begin{tabular}{|c|c|c|c|c|c|c|c|c|}
\hline DATE & $\begin{array}{l}\text { TEST } \\
\text { NUMBER }\end{array}$ & & TEST OBUECTIVES & $\begin{array}{l}\text { COAL } \\
\text { BURN TIME } \\
\text { (hr:min) }\end{array}$ & $\begin{array}{l}\text { ENERGY } \\
\text { GENERATED } \\
\text { (MW hr) }\end{array}$ & $\begin{array}{l}\text { PEAK } \\
\text { POWER } \\
\text { (MW.' }\end{array}$ & $\begin{array}{l}\text { POWER } \\
\text { RUN TIME } \\
\text { (hr:niiai) }\end{array}$ & ZUMMENTS \\
\hline $04: 28 / 21$ & 81.SREJ. 1 & $\begin{array}{l}11 \\
21 \\
31\end{array}$ & 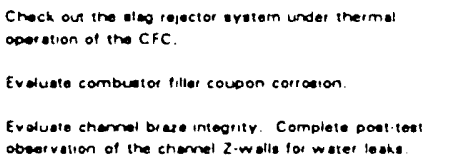 & $1: 28$ & 0.00 & 0.00 & 0000 & 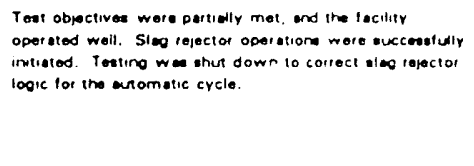 \\
\hline $06 \% 1 / 81$ & Q1.SREJ.2 & 11 & Same objectiveo $\approx$ O I SREJ.1. & $5: 36$ & 0.00 & 0.00 & 0000 & 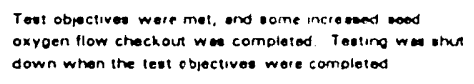 \\
\hline C603:0: & O1.SEEO.1 & $\begin{array}{l}21 \\
41\end{array}$ & 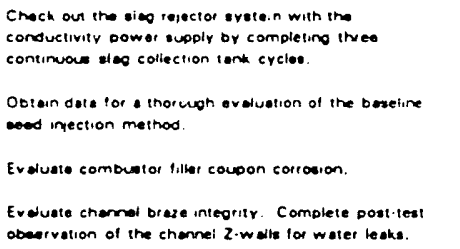 & $1: 13$ & 0.00 & 0.00 & 00.00 & 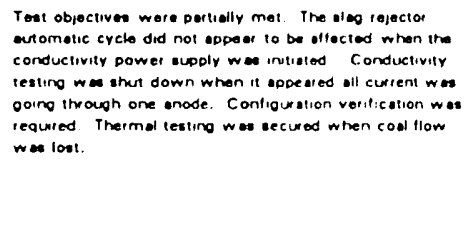 \\
\hline $06 / 07.01$ & OS.SEED.2 & 11 & Same objectives of 81.SEED-1. & 4:32 & 0.00 & 0.00 & 00.00 & 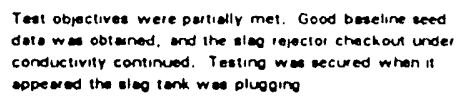 \\
\hline 060001 & O1.SEEO.3 & $n$ & Serme objectives an PI.SEED. 1. & 4:10 & 000 & 0.00 & $00: 00$ & 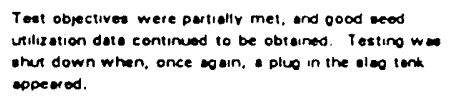 \\
\hline $06 / 14 / 81$ & 91.CALB.1 & 3 & 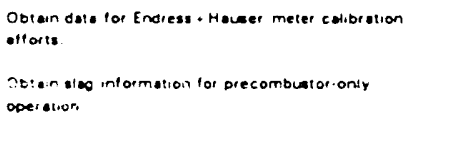 & $0: 17$ & 0.00 & 0.00 & $00: 00$ & 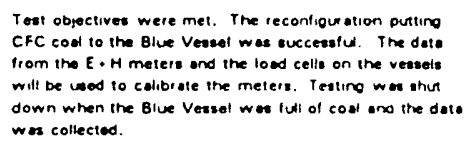 \\
\hline $06 / 16 / 91$ & DISREJ 3 & $\begin{array}{l}\text { "1 } \\
31 \\
41 \\
61\end{array}$ & 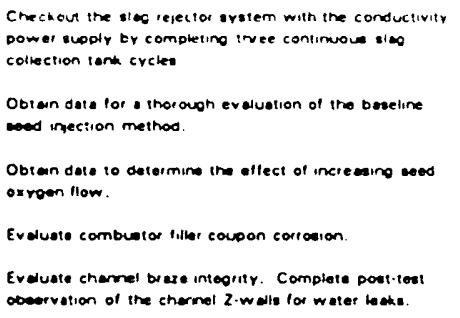 & 644 & 0.00 & 0.00 & 00.00 & 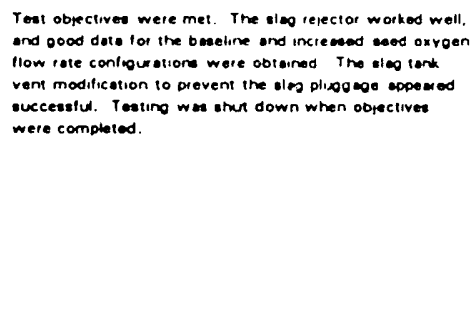 \\
\hline $06 / 10 / 91$ & O. SREJ.A & $" 1$ & Surne obpectiven $\approx 21$. SRES. 3. & 4:36 & 0.00 & $0 . \infty$ & $\infty: \infty$ & 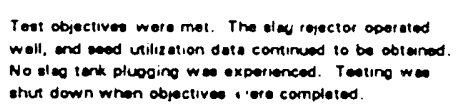 \\
\hline $05 / 1701$ & $01 . \cos \cdot{ }^{\prime}$ & $\begin{array}{l}11 \\
21 \\
31\end{array}$ & 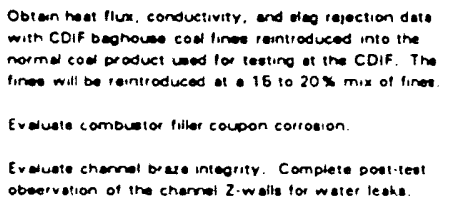 & $2: 32$ & 0.00 & 0.00 & $\infty: \infty$ & 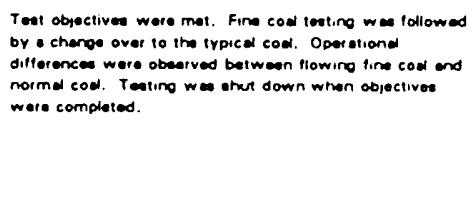 \\
\hline
\end{tabular}


tank dump, did not complete in automatic mode. After manual completion of the denseveyor dump and the collection tank dump, the system was returned to automatic. The required three collection tank dumps were then completed without further problems. The source of the problem on the first and second cycle is unknown. Data shows the time between cycles to be 30 minutes (as was designed), plus up to 10 seconds and minus up to 5 seconds. Again, these differences are insignificant, and the cycles were regular.

Test 91-SEED-2 continued Phase II testing of the slag rejection system under simulated electrical conditions. A baseline of conductivity with varying amounts of seed flow was conducted.

The slag rejection system went through a total of eight denseveyor dumps and three collection tank dumps in automatic without problems. Consequently, the slag rejection system checkout goal was met. The blockage that forced the test to be secured is believed to be unrelated to the slag rejection system.

The purposes of test 91-SEED-3 were to continue slag rejector checkout and to conduct a seed sweep similar to test 91-SEED-2 at a first-stage equivalence ratio (phi 1) of 0.60 instead of 0.55 . The change in equivalence ratio was an attempt to make the first stage run hotter to avoid plugging in the slag tank. This attempt was unsuccessful.

The combination of the last test (91-SEED-2) and test 91-SEED-3 was an opportunity to determine the effects of first-stage equivalence ratio changes of bulk plasma resistance at various seeding levels.

The effects of iron oxide slurry injection on channel conductivity was noted during test 91-SREJ-3. Several seed-off transients were done including one in which iron oxide was being injected while seed was secured and the conductivity decay was observed.

Test 91-COAL-1 involved injecting coal fines that are usually removed prior to combustion. The test was run with minimal variations to obtain baseline data. The bulk plasma resistance (defined as the channel end-to-end voltage divided by the conductivity current) for this test was generally around 22 ohms but varied by plus and minus several ohms throughout the test. This contrasts with about 26 ohms for similar conditions during test 91-SEED-3. However, a major difference is that iron oxide slurry was injected during this test but not during test 91-SEED-3. Iron oxide is known to have the effect of reducing apparent resistance by increasing slag conductivity. Since this effect was not quantified, there is no way to determine if the injecting fine coal had any affect on conductivity or whether the resistance decrease is due solely to iron oxide injection.

The test series that concluded with test 91-COAL-1 was run exclusively with conductivity; no power generation was done. 


\subsubsection{Subtask 3B -- Unassigned}

\subsubsection{Subtask 3C -. Data Analys is and Modeling}

\subsubsection{CDIF Plasma/Slag Calculations}

MSF personnel have developed an advanced, one-dimensional, electrical model (ELECID) for 1 inear MHD generators that is capable of calculating many plasma/slag properties of the CDIF generator directly from routine electrical measurements taken during a load sweep. This new mode?, applicable to both Faraday and diagonal modes, is based on appropriately averaging the plasma/slag properties on each one-pitch control volume using the proper weight functions. This approach results in the natural introduction of both primary and secondary nonuniformity factors to account for the plasma/slag nonuniformities that exist in MHD generators. Since these nonuniformities are primarily responsible for the large axial and transverse power losses that are believed to exist in coal-fired MHD generators, this model represents a significant advancement over previous one-dimensional models in terms of accuracy and simplicity (explicit internal voltage drops and current leakage terms are not needed in the model).

Among the channel properties that can be estimated on a per-pitch basis using the model are the average conductivity, the average Hall parameter, the channel axial and transverse resistances, and the primary and secondary nonuniformity factors--all under power generation conditions. As an illustration, Figures 1 and 2 show the average conductivity and Hall parameter, respectively, for test $90-\mathrm{CC}-4$ that was calculated from the electrical data generated over a load sweep. The averages shown in these plots were calculated at every 20th electrode and include both slag layer and finite segmentation effects. A detaile. explanation of the model and its application to CDIF test results appears in two recent papers by $V$. W. Daniel: "CDIF Plasma/Slag Calculations," presented at the 29th SEAM in New Orleans, Louisiana, and "Estimating Plasma/Slag Properties from CDIF Electrical Measurements," presented at the AIAA 22nd Fluid Dynamics, Plasma Dynamics, and Lasers Conference in Honolulu, Hawaii.

\subsubsection{CDIF Statistical Analys is}

MSE personnel are now using the Statistical Analysis System (SAS) statistical package, which is a new software package, to analyze CDIF test data. For the MHD iest program, SAS will be used mainly to determine trends that are statistically significant and to determine which control variables affect which response variables. For 


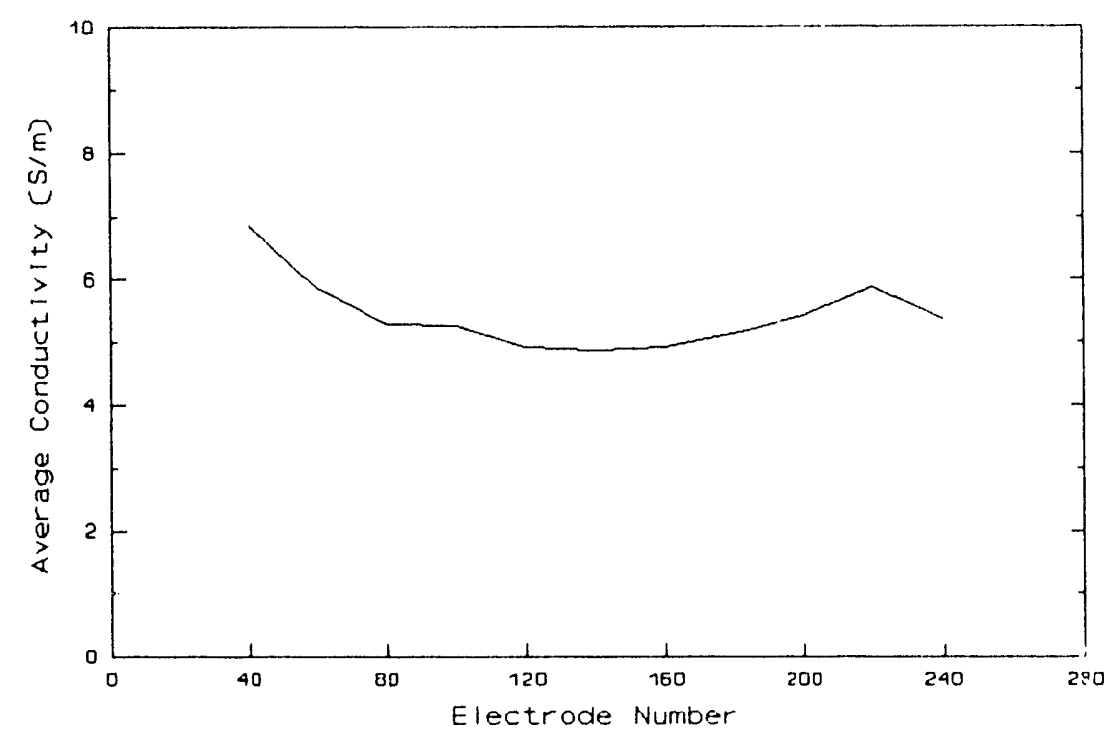

Figure 1 -- Average Conductivity for Test 90-CC-4 calculated from electrical data generated over a load sweep.

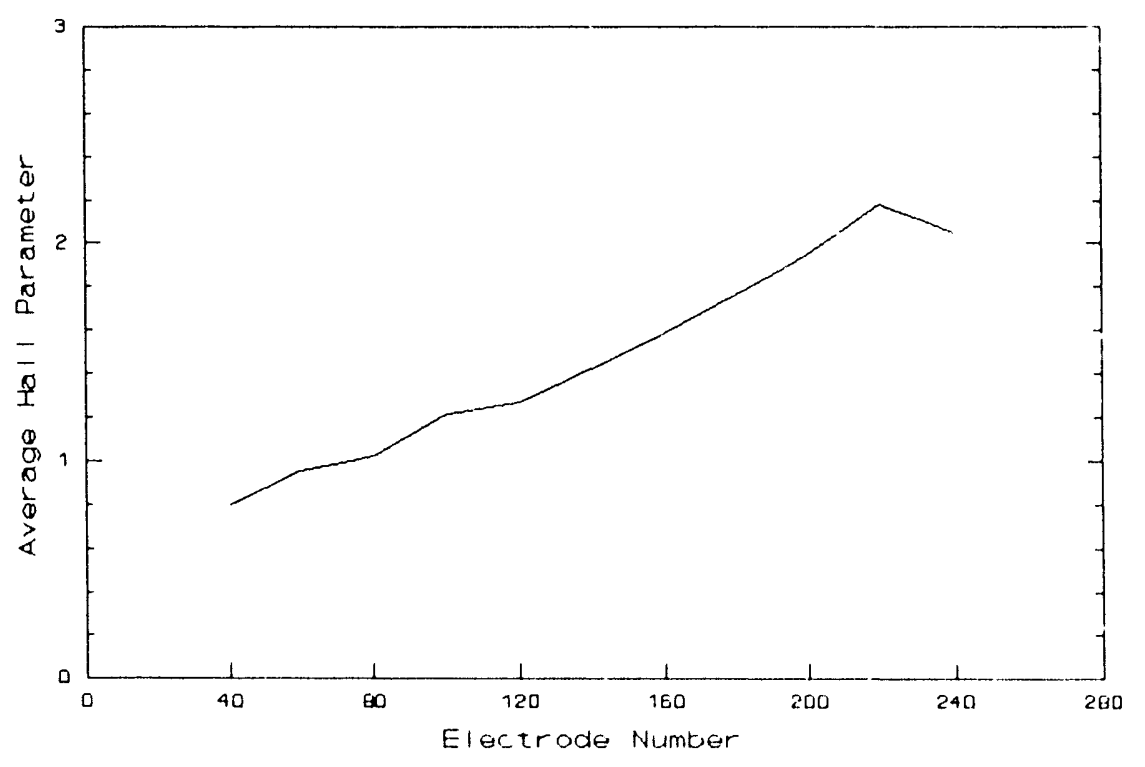

Figure 2 -- Average Hall parameter for Test 90-CC-4 calculated from electrical data generated over a load sweep. 
each test or group of tests analyzed, various regression models will be examined to find a model statistically valid over the test data range. The residuals (errors) resulting from the fitted models will be checked for autocorrelation (time trends) and normality (errors normally distributed about mean 0 ). In this way, trends and relations observed in the past can be statistically validated as well as (possibly) many new ones that previously escaped detection.

\subsubsection{Pipe Network Flow Program and CDIF Magnet Cooling Water Flow Calculation}

A pipe network flow program was developed to support the possible engineering requirement of cooling water system calculation and analysis. The Pipe System Flow Analysis (PSFA) program is a menu driven, interactive program for developing and analyzing pipe systems. PSFA will calculate the rate of flow through each pipe in the system using the Newton-Raphson iteration method and takes into consideration minor losses due to pipe friction, valves, and fittings.

The PSFA program was used to calculate the magnet cooling flow distribution during the recent investigation of the magnet cooling water leak. First, the program was used to match the acceptance test output and obtain the baseline individual cooling water flow rate. Next, a sensitivity study was done to determine the minimum cooling water flow rate required for sufficient cooling of the coils. Finally, the actual flow test was executed, and the data was compared with the baseline data. No significant flow blockage was found. The defective hose fitting was reinstalled to see how much blockage this fitting could produce. The results show that there was no significant cooling flow loss due to the defective fitting. Detailed information on this project can be found in the final report of the magnet cooling water leak investigation and repair project.

\subsubsection{Magnet Vacuum Purging and Water Measurement Study}

A concern that water was trapped in the CDIF magnet and the east-side cooling water passages was causing the low resistance readings to ground prompted a proposal to use vacuum equipment to evacuate the magnet cooling water passages, boil off any water present, and condense the water in a low temperature condenser to verify that water was or was not present. An analysis was performed to determine the necessary conditions (temperature and pressure) in the condenser that were required to ensure capture of any water evaporated from the magnet. The desired pressure was specified as $300 \mathrm{milli}$-torr since an existing vacuum pump of that rating was to be used. From calculated saturation temperature at this pressure, the 
use of liquid nitrogen or carbon dioxide ice was recommended for chilling the condenser. A number of recommendations were also made on proper condenser design and test procedure needed to accomplish the desired results. The results of this analysis were reported in an internal report titled "Analysis and Recommendations for Vacuum Purging and Water Measurement for CDIF Iron Core Magnet" by Gloyd Simmons.

\subsubsection{MHD Channel AFT Power Take-Off (PTO) Region Study}

An analysis of the modification to the aft PTO region of the channel was performed using a two-dimensional channel electrical simulation computer code (ELEC2D). A tctal of 11 cases were run, which included the original request, MSE variations on it to obtain better results, and parametrics on the MSE-selected case to evaluate its sensitivity to parametric changes. Also, instrumentation needs, including both sensor locations and ranges, were evaluated. On the basis of recommendations made, the original request was simplified, proper ranges for the instruments were selected, and test personnel have an idea of what to expect. This configuration will be tested next quarter.

\subsubsection{Voltage Sensors and DC Magnetic Field Interaction Study}

Voltage data was collected on the DAS from three different areas of the channel, including a $Z$-sidebar region, a 4segment straight sidebar region, and a 3 -segment straight sidebar region. A least-squares technique of data reduction was applied to this data to check for errors, reduce noise, and make the data internally consistent. This technique worked well for two of the groups, but the third continued to have noticeable remaining errors. Investigation showed the voltage sensors for this group were being affected by the dc magnetic field fringe lines. This error proved to be highly repeatable, and a technique was developed to remove this error source before application of the least-squares algorithm. This technique brought the errors associated with this group in line with the other two unaffected groups.

A paper was written and presented in the poster session of the 1991 SEAM conference. "Developments in Channel Power at the Component Development and Integration Facility" covered topics such as the least-squares analys is (described above), present CDIF capabilities, the current controls installation, the inverter voltage transient investigation, and the upcoming POC channel and current consolidation installations. 


\subsection{TECHNICAL PAPERS}

Six papers were presented at the SEAM Conference held June 17-21, 1991, in New Orleans, Louisiana. Authors and titles are:

Ashby, G.; Lohrasbi, J.; and Walter, F., "An Economic Analysis of Coal-Fired Magnetohydrodynamics."

Cott, D. and Lohrasbi, J. "Slagging MHD Generators: A New Wall Design Philosophy for Improved Lifetime and Performance."

Cott, D.; Rudberg, D.; and Williamson, R., "High Explosive MHD Pulsed Power." Daniel, V.W., "CDIF Plasma/Slag Calculations."

Harned, D.; Lofftus, D.; and Verbae1, D., "Developments in Channel Power at the CDIF."

Hart, A. and Alsberg, C., "Coal-Fired MHD Test Progress at the Component Development and Integration Facility."

Miller, A., "CDIF Facility Preparedness for Testing of Proof-of-concept Hardware."

Don Cott was selected to receive the Jean F. Louis Memorial Award for the best formal presentation of the 29th Symposium on Engineering Aspects of MHD.

\subsection{PROJECTED ACTIVITIES}

Facility (Task 1) activities planned for the fourth quarter of FY91 include:

- installing the primary injector vent lines and pulverizer feeder modifications on the coal system;

- completing calibration procedures for the storage injector level switch;

- completing modifications on the seed storage silo;

- completing preliminary installation of the $K C$ building and finalizing preparations for the acceptance of the anode KC cabinets;

- finalizing the subcontract for the oxygen system upgrade and initiating the system operating test procedure;

- awarding the subcontract for internal repairs of the ICM and finalizing evaluation of the low resistivity of the east coil; and

- initiating subcontracts for installing the CDIF slag removal equipment.

Test hardware support (Task 2) activities planned for the fourth quarter of FYgl include:

- refurbishing the $1 A_{1}$ channel for the fall test series. 
Test operations (Task 3) activities planned for the fourth quarter of FY9l include:

- completing test preparations for fall startup; and

- initiating startup testing including facility checkout. 

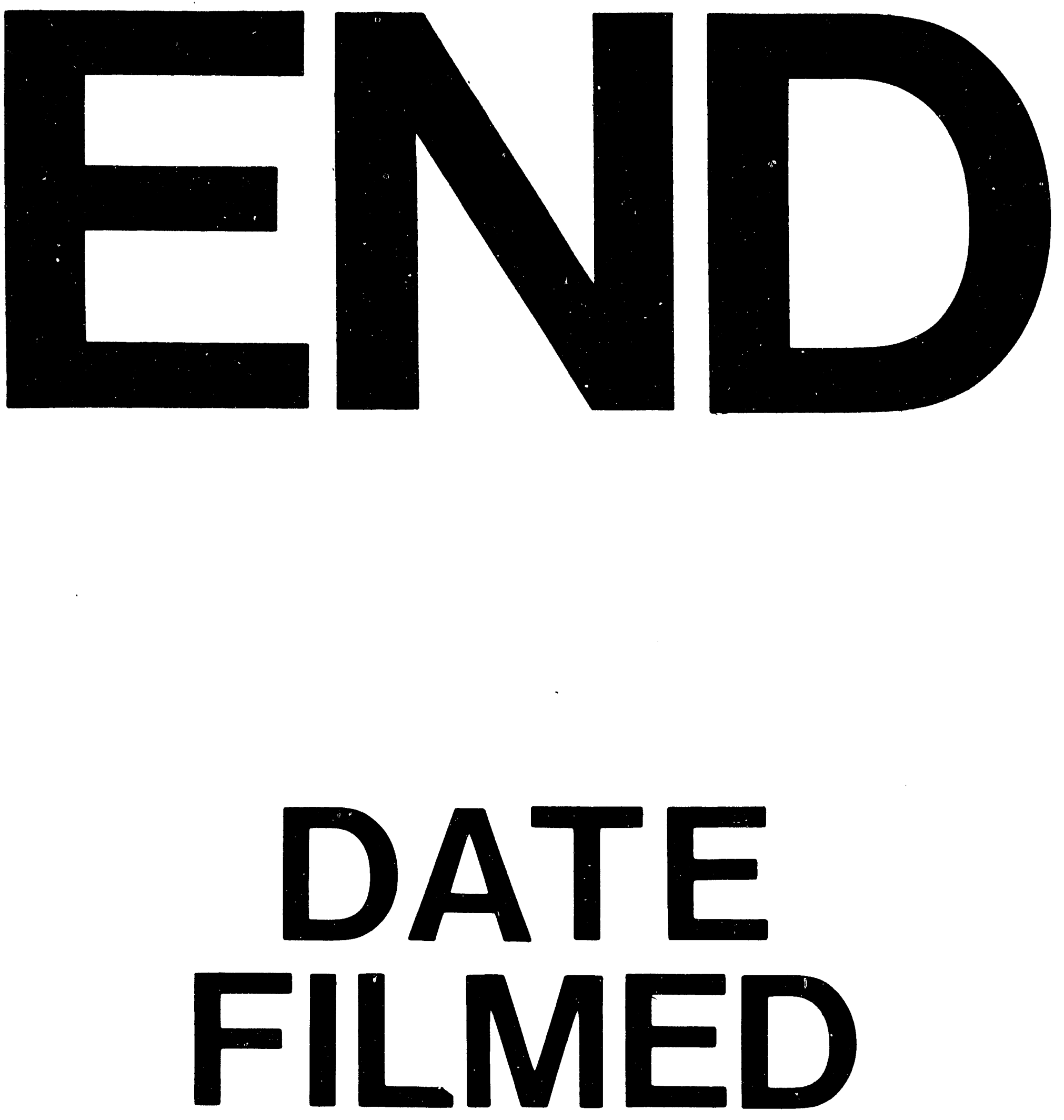

1

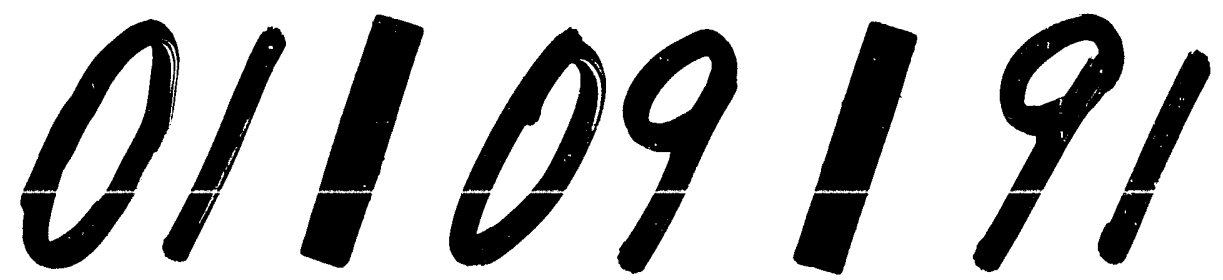

$\ldots$ 
